1. Senior Demonstrator Department of Physiology

University College of Medicine and Dentistry (UCMD),

The University of Lahore-Pakistan

2. Assistant Professor Department of Physiology Independent Medical College Faisalabad-Pakistan

3. Assistant Professor Department of Physiology University College of Medicine and Dentistry (UCMD),

The University of Lahore-Pakistan

4. Professor

Professor of Biochemistry Institute of Molecular Biology and Biotechnology,

University of Lahore, Lahore, Pakistan

5. Student M. Phil

Institute of Molecular Biology and Biotechnology, University of Lahore, Lahore, Pakistan

Correspondence Address: Arif Malik (PhD)

Institute of Molecular

Biology and Biotechnology,

University of Lahore, Lahore, Pakistan arifuaf@yahoo.com

Article received on: 14/07/2016

Accepted for publication: 15/09/2016

Received after proof reading: $14 / 11 / 2016$

\section{CARDIOVASCULAR DISEASES; INTERRELATIONSHIP OF EXTRAPOLATIVE VARIABLES AND THEIR POTENTIAL ROLE IN THE DEVELOPMENT: STUDY FROM THE LOCAL POPULATION OF PUNJAB PAKISTAN \\ arifuaf@yahoo.com}

\begin{abstract}
Muhammad Abdul Basit Ashraf', Razia Rizwan², Mahwish Arooj ${ }^{3}$, Arif Malik ${ }^{4}$, Sarmad Bashir ${ }^{5}$
\end{abstract}
ABSTRACT: Background: Atherosclerosis, with chief contribution of vascular injury, inflammation and oxidative stress is the major cause of majority of cardiovascular diseases. Understanding of its pathophysiology provides initial prognosis, designing of new therapeutics for its prevention and different treatment protocols. Objectives: The present study was designed to evaluate the role of oxidative and inflammatory markers of medical importance in the development of cardiovascular diseases. Study Design: Prospective case control study. Setting: Sample collection from Punjab Institute of Cardiology (PIC), Lahore and all the experimental work was done at Institute of Molecular Biology and Biotechnology (IMBB), The University of Lahore. Period: February 2015 to April 2016. Methodology: Biophysical, hematological, antioxidative capacity, inflammatory markers and lipid profile were estimated in atherosclerotic patients. Results: The BMI $(31.26 \pm 1.66)$ were significantly increased in atherosclerotic patients when were compared with controls. MDA was recorded as $3.99 \pm 0.16$ in atherosclerotic patients followed by $1.66 \pm 0.11 \mathrm{nmol} / \mathrm{ml}$ in healthy control respectively. Nitric oxide (NO) in the patients $(35.26 \pm 4.26 \mathrm{ng} / \mathrm{ml})$ was also significantly raised in the patients than normal subjects $(21.26 \pm 2.35 \mathrm{ng} / \mathrm{ml})$. Whereas mean serum levels of MPO and AGEs in patients were $0.237 \pm .0013 \mathrm{pmol} / \mathrm{ml}$ and $2.46 \pm 0.09 \mathrm{U} / \mathrm{ml}$ respectively. Increased levels of TCh $(217.56 \pm 10.99$, TG (199.67 \pm 11.02$)$, and LDL (131.87 \pm 9.56$)$ along with decrease in HDL $33.76 \pm 3.85 \mathrm{mg} / \mathrm{dl}$ were recorded respectively. The hs-CRP showed significant increased levels in atherosclerotic group $(3.93 \pm 0.14 \mathrm{mg} / \mathrm{dl})$ as compared to normal control $(1.68 \pm 0.06 \mathrm{mg} / \mathrm{L})$. The mean serum level of TNF-a and IL-6 in diseased group was recorded as $41.25 \pm 3.65 \mathrm{pg} / \mathrm{ml}$ and $6.35 \pm 0.64 \mathrm{pg} / \mathrm{ml}$ respectively. The significant decreasing trend of total anti-oxidant capacity, SOD, CAT, GSH, GPx, GRx, vitamin A and C but increasing drift of vitamin E was observed in atherosclerotic patients. Conclusion: Following study reported that elevated oxidative stress and inflammation along with lipid peroxidation are the major contributors in the progression of atherosclerosis.

Key words: $\quad$ Atherosclerosis, oxidative stress, advanced glycated end-products (AGEs), myeloperoxidase (MPO).

Article Citation: Ashraf MAB, Rizwan R, Arooj M, Bashir S, Malik A. Cardiovascular diseases; interrelationship of extrapolative variables and their potential role in the development: study from the local population of Punjab Pakistan. Professional Med J 2016;23(11):1400-1411. DOI: 10.17957/TPMJ/16.3527

\title{
INTRODUCTION
}

Most vascular diseases like coronary artery disease, peripheral artery diseases etc. involve atherosclerosis that may be caused by hypertension, smoking, physical inactivity, obesity, hypercholesterolemia, malnutrition, diabetes and excessive alcohol consumption. Atherosclerosis is a progressive inflammatory disease caused by fat deposition, inflammatory interventions that lead to endothelial dysfunction and plaque formation inside the arterial walls. ${ }^{1}$
Endothelial dysfunctions predispose to atherosclerotic lesions and the key feature of the atherothrombotic process involved in the etiology of causing disease is the generation of reactive oxygen species (ROS) along with decrease levels of antioxidant capacity due to increased utilization of these anti-oxidants in scavenging the lipid peroxides. ${ }^{2,3}$ Reactive oxygen species upregulate the expression of many pro-inflammatory molecules that facilitate inflammatory processes 
and lipid accumulation in the arterial wall. ${ }^{4}$ ROS affect vascular functions through hydroxyl free radicals $(\mathrm{OH}-)$ formation results in lipid peroxidation by oxidizing lipid components leading to the formation of oxidized lipoproteins (Ox-LDL), the key mediator of atherosclerosis. ${ }^{5}$

The oxidized LDL is endocytosed by subendothelial macrophages through specific scavenger pathway forming foam cells in arterial wall. The initial visible lesion of atherosclerosis is fatty streaks formed by accumulation of lipidladen foam cells in the inner vascular layers which further advance to fibrous plaque formation. The atherosclerotic plaque can be separated from arterial lumen by fibrous cap consists of extracellular matrix and smooth muscle cells. ${ }^{6}$ Some components of Ox-LDL such as oxysteral, oxidized fatty acids and aldehydes are involved in ROS generation in vascular wall. The Ox-LDL also upregulated the expression of TNF-a and interleukins involved in vascular smooth muscle cells (VSMCs) proliferation. Lipid peroxides formed are also involved in the inhibition of prostacyclin which ultimately causes platelet adhesion and aggregation forming advanced lesion. ${ }^{7}$ The advanced lesion can grow large to block the blood flow and are more susceptible to rupture in increased shear stress that is caused by increased intra luminal pressure and narrowing of coronary arteries. ${ }^{8,9}$ The present study was designed to assess the interrelationship of extrapolative variables and their potential role in the development of atherosclerosis.

\section{METHODOLOGY}

The present study was conducted during February 2015 to April 2016. For this propose fifty patients of atherosclerosis were screened/ selected at Punjab Institute of Cardiology Lahore (PIC). Informed consent was received before being included in this study. Twenty healthy age matched individuals were selected which served as controls. Whole of the experiment/protocols were conducted at the Institute of Molecular Biology and Biotechnology (IMBB) and Centre for Research in Molecular Medicine (CRiMM), The University of Lahore. About $5 \mathrm{ml}$ of venous blood was drawn from the anticubital veins of individuals.
After the blood was drawn it was then centrifuged within the time of one hour of collection, so that their serum are separated properly and were then stored at temperature of $-70^{\circ} \mathrm{C}$ until assays are performed. Patient inclusion criteria were based on the following points: 1) patients must be of age 20-70 years 2) All ischemic heart disease patients were included in the study whereas their history like if they take any drugs (Alcohol or cigarette) or their pre-diagnosis medications (e.g. aspirin, lipid lowering drugs etc), were excluded out of this study. Afterwards their following variables were performed by appropriate methods of: $\mathrm{GSH}$, Catalase, SOD, MDA, GPx, GRx, Vit-E, Vit-A, Vit-C, NO, AGEs and MPO. TNF-a (BioVendor Human TNF-a ELIZA Kit), IL-6 (BioVendor Human IL-6 ELIZA Kit), lipid profile (TCh, TG, LDL, HDL) is determined by Commercial Human Diagnostics Kits.

\section{BIOCHEMICAL ANALYSIS}

GSH determination in patients was done by the method of Moron et al., (1979). ${ }^{10}$ Evaluation of Catalase was according to the method of Aebi (1974). ${ }^{11}$ Determination of Superoxide Dismutase by the method of Kakkar (1984). ${ }^{12}$ Glutathione peroxidases were assayed by the method described by Wendel (1980). ${ }^{13}$ Evaluation of glutathione reductase was executed as per the method of David and Richard (1983). ${ }^{14}$ Evaluation of vitamin $\mathrm{E}$ in liver samples with Emmerie-Engel reaction was reported by Rosenberg (1992)..$^{15}$ Evaluation of vitamin A was done with the help of Bayfield and Cole (1980) method. ${ }^{16}$ Chinoy et al. (1976) method was used for estimation of vitamin C. ${ }^{17}$ Advanced glycation end products (AGEs) was evaluated by the method of Goldin et al. (2006). ${ }^{18}$ Estimation of Malondialdehyde Serum MDA level was measured according to the method of Ohkawa et al. (1979). MDA level was determined by thiobarbituric acid reactive substances (TBARS) in serum, based on the reaction between MDA and TBARS. ${ }^{19}$ The MPO is evaluated by the help of their particular ELISA assays its principle based on the solid phase ELIZA (Enzyme-Linked Immunosorbent Assay) and their absorbance was taken at $450 \mathrm{~nm} .{ }^{20}$ The interleukin- 6 concentration was assayed by the quantitative ELISA (Enzyme Linked Immunosorbent Assay) as mentioned by their manufacturers' protocols (R\&D Systems, 
Minneapolis, MN, USA). ${ }^{21}$ Lipid profile (TCh, TG, LDL and HDL) were estimated by the method of Friedewald (1972). ${ }^{22}$ The levels of tumor necrosis alpha (TNF-a) were determined using commercial ELISA kits (Affimatrix, Japan) and was expressed in units $(\mathrm{pg} / \mathrm{ml})^{23}$.Serum NO (nitrite) levels were measured using the Griess reagent method. ${ }^{24}$

\section{STATISTICAL ANALYSIS}

The study design was prospective case control and the data was analyzed statistically by SPSS (V16) and expressed as mean \pm SD. Independent t-test was applied to analyze the results between patients of cardiovascular diseases and health subjects. Pearson's correlation coefficients were used to correlate different variables. $\mathrm{P}<0.05$ is considered to be statistically significant.

\section{RESULTS}

Data analysis in figure $01(\mathrm{~A})$ represented that the mean ages of normal and diseased patients were $51.26 \pm 4.26$ Yrs and 50.26 \pm 4.11 Yrs respectively. Atherosclerosis mean weight of the patient $(81.26 \pm 7.25 \mathrm{~kg})$ was high than normal individuals $(69.25 \pm 3.25 \mathrm{~kg})$ and diseased patients showed the high levels of BMI $\left(31.26 \pm 1.66 \mathrm{~kg} / \mathrm{m}^{2}\right)$ than controls $\left(20.15 \pm 2.22 \mathrm{~kg} / \mathrm{m}^{2}\right)$, shown in figure 01 ( $B$ and $C)$. Age was insignificant $(p=.451)$ while weight and BMI were significant as $p=0.046$ and $p=0.001$ respectively. The systolic and diastolic blood pressures in subjects were recorded $(131.25 \pm 3.09$ and $97.65 \pm 7.25)$ as compared to control (124.26 \pm 1.98 and $83.25 \pm 2.95)$ and both were statistically significant $(p=0.005$ and $p=0$ 015 respectively).

\section{BLOOD COUNT OF CONTROL Vs \\ ATHEROSCLEROTIC PATIENTS}

Figure-1 (D) showed lower levels of RBCs $\left(4.96 \pm 0.25 \mathrm{~mm}^{3}\right)$ in disease patients than controls $\left(5.26 \pm 0.95 \mathrm{~mm}^{3}\right)$ and statistically insignificant $(p=0.095)$. Atherosclerotic patients reported insignificant $(p=0.439)$ increase in WBCs $\left(7.66 \pm 1.11 \mathrm{~mm}^{3}\right)$ than normal patients $\left(7.26 \pm 1.23 \mathrm{~mm}^{3}\right)$, as represented in figure-1 (E). Atherosclerotic patients had $\mathrm{Hb}$ levels $(16.26 \pm 2.22 \mathrm{~g} / \mathrm{dl})$ while healthy people had $\mathrm{Hb}$ levels $(14.26 \pm 2.16 \mathrm{~g} / \mathrm{dl})$, statistically insignificant $(p=0.210)$.

STRESS BIOMARKERS PROFILE OF

ATHEROSCLEROTIC PATIENTS VS CONTROL

Data analysis regarding oxidative stress biochemical markers MDA, NO, AGEs and MPO shows highly significant pattern between and within the groups. The MDA level in atherosclerotic patients was $3.99 \pm 0.16 \mathrm{nmol} / \mathrm{ml}$ while in control group was $1.66 \pm 0.11 \mathrm{nmol} / \mathrm{ml}$ with a significance of $p=0.027$. Nitric oxide in diseased patients $(35.26 \pm 4.26 \mathrm{ng} / \mathrm{ml})$ is remarkably $(p=0.027)$ increased as compared to normal subjects $(21.26 \pm 2.35 \mathrm{ng} / \mathrm{ml})$. The mean serum levels of AGEs and MPO in diseased patients were $2.46 \pm 1.87 \mathrm{U} / \mathrm{ml}, \quad 0.237 \pm 0.0013 \mathrm{pmol} / \mathrm{ml}$ and in normal individuals were $0.71 \pm 0.011 \mathrm{U} / \mathrm{ml}$, $0.103 \pm .0079 \mathrm{pmol} / \mathrm{ml}$, having significance $\mathrm{p}=$ 0.038 and $p=0.001$ respectively.

\section{ANTI-OXIDANTS BIOMARKERS PROFILE OF ATHEROSCLEROTIC PATIENTS Vs CONTROL} The significant $(p=0.031)$ decreasing trend of SOD was recorded in atherosclerotic patients $(1.98 \pm 0.04 \mu \mathrm{g} / \mathrm{dl})$ as compared to normal individuals $(3.33 \pm 0.09 \mu \mathrm{g} / \mathrm{dl})$. Serum CAT levels in diseased individuals were $2.01 \pm 0.06 \mu \mathrm{mol} / \mathrm{mol}$ of protein as compared to control $(2.99 \pm 0.08 \mu \mathrm{mol} /$ mol of protein) and was highly significant $(p=$ 0.013). Vitamin $E$ measured in atherosclerotic patients was $1.15 \pm 0.06 \mu \mathrm{g} / \mathrm{dl}$ and in healthy persons was $0.18 \pm 0.03 \mu \mathrm{g} / \mathrm{dl}$, having significance (0.005). Vitamin A level in diseased patients decreases as compared to controls and is found significant $(p=0.044)$. Diseased atherosclerotic patients showed decrease levels of Vitamin C $(0.16 \pm 0.005 \mu \mathrm{g} / \mathrm{dl})$ and control individuals show elevated pattern $(0.36 \pm 0.009 \mu \mathrm{g} / \mathrm{dl})$ with a significance of $p=0.006$. The GPx level and GRx levels of atherosclerotic patients are showing a decreasing trend as compared to normal person and statistically significant. The patients had low levels of GSH $(4.26 \pm 0.453)$ due to its activity in neutralizing the ROS by donating its electrons and become oxidized, and control patients shows highly significant $(p=0.001)$ high levels of $\mathrm{GSH}$ $(9.08 \pm 0.675 \mu \mathrm{g} / \mathrm{dl})$. 


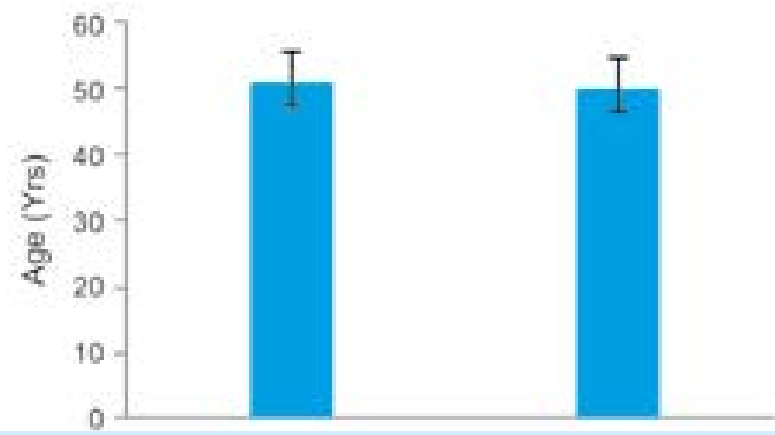

Figure (A)

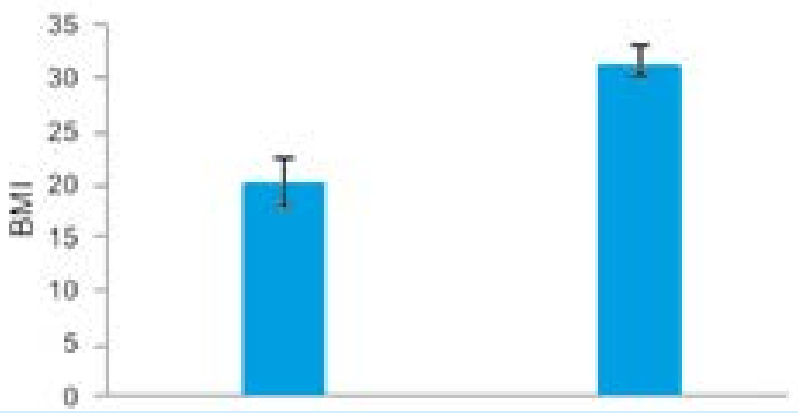

Figure (C)

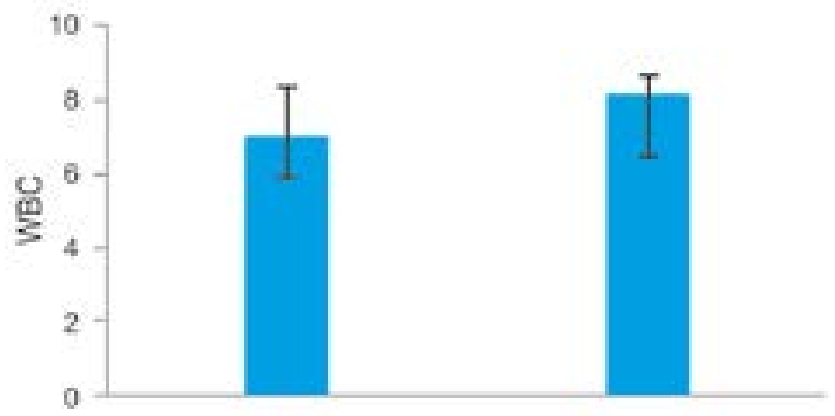

Figure (E)

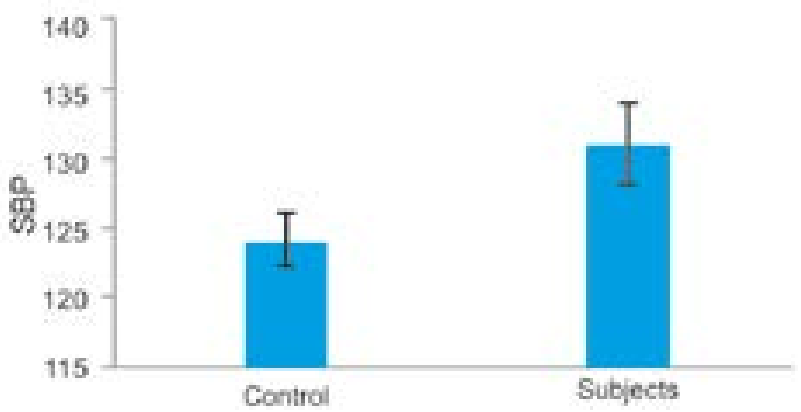

Figure (G)

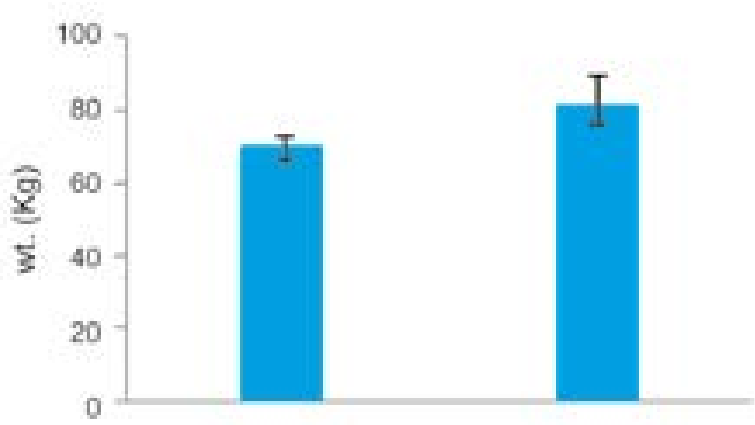

Figure (B)

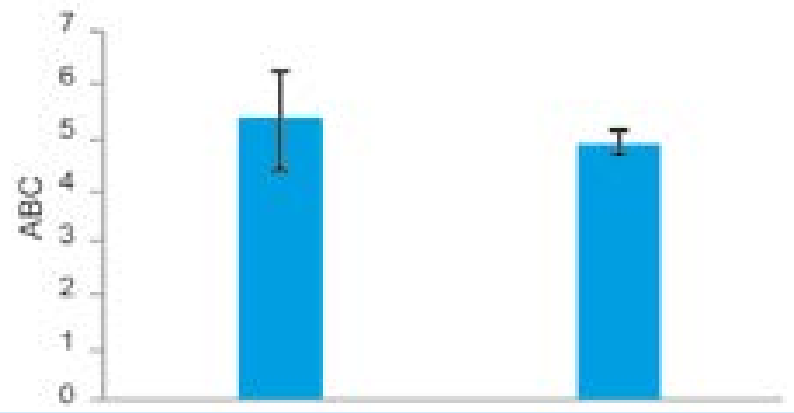

Figure (D)

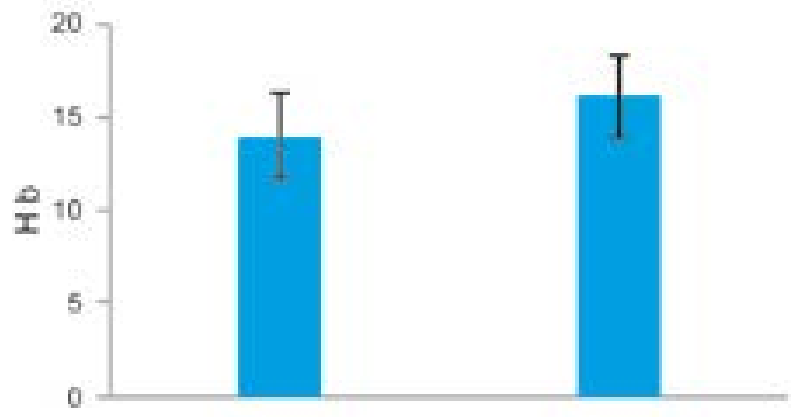

Figure (F)

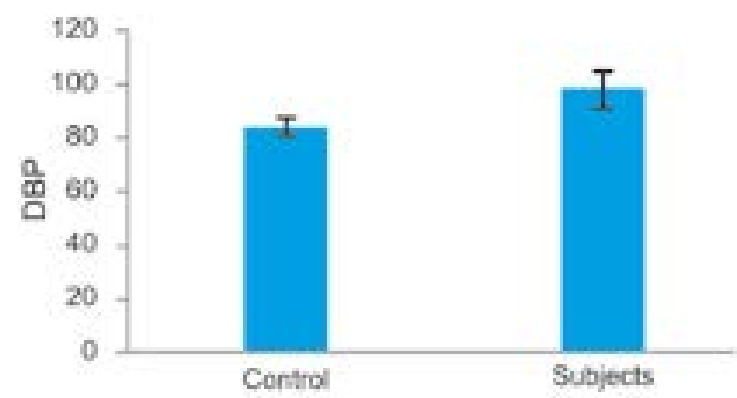

Figure (H)

Figure-1. Physical and heamatological variables of patients with cardiovascular diseases 
The patients of atherosclerosis showed the low levels of TAC $(0.67 \pm 0.034 \mathrm{mmol} / \mathrm{L})$ and controls show significantly $(p=0.035)$ increased levels

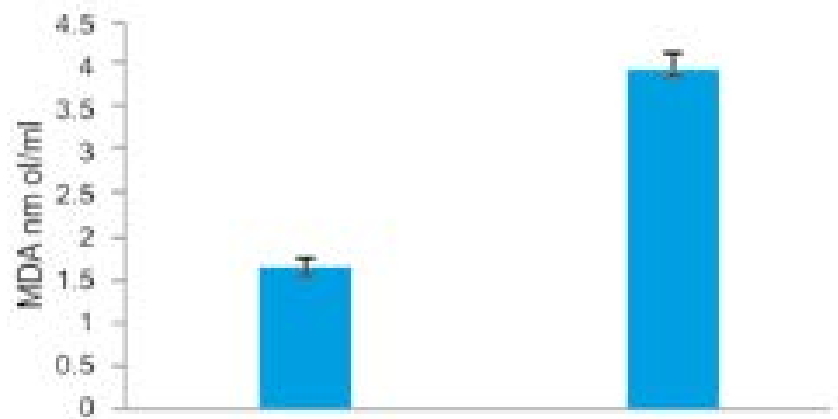

Figure (A)

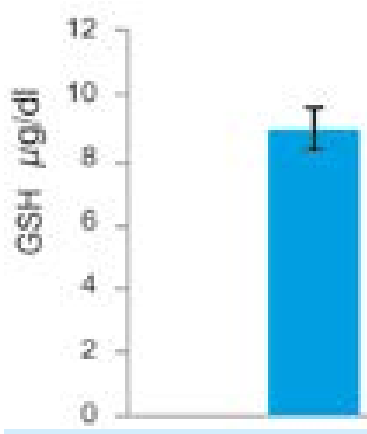

Figure (C)

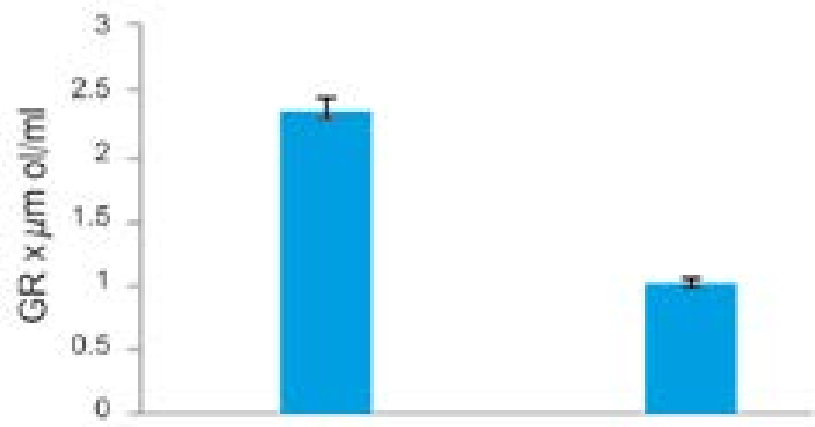

Figure (E)

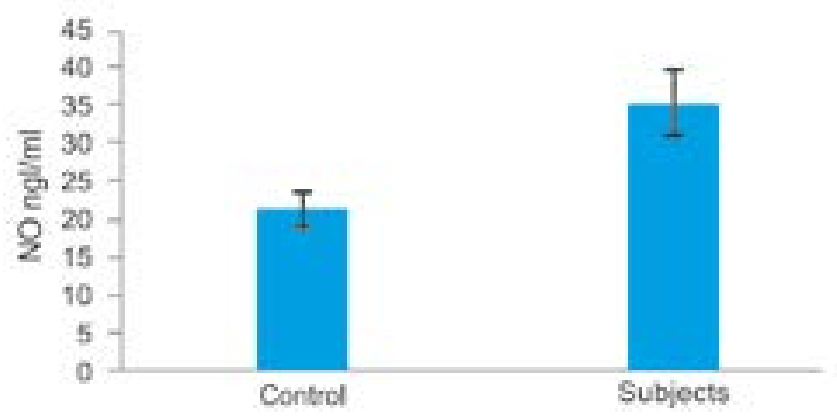

Figure (G) of TAC $(1.43 \pm 0.056 \mathrm{mmol} / \mathrm{L})$. The graphical representation of these markers was illustrated in figure-2.

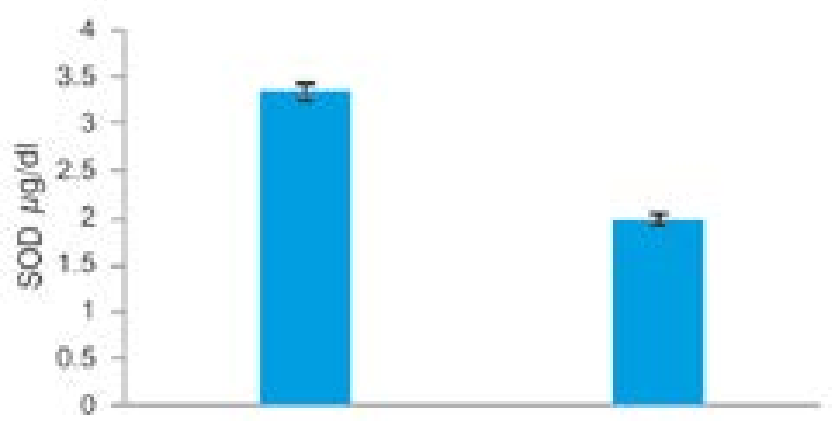

Figure (B)

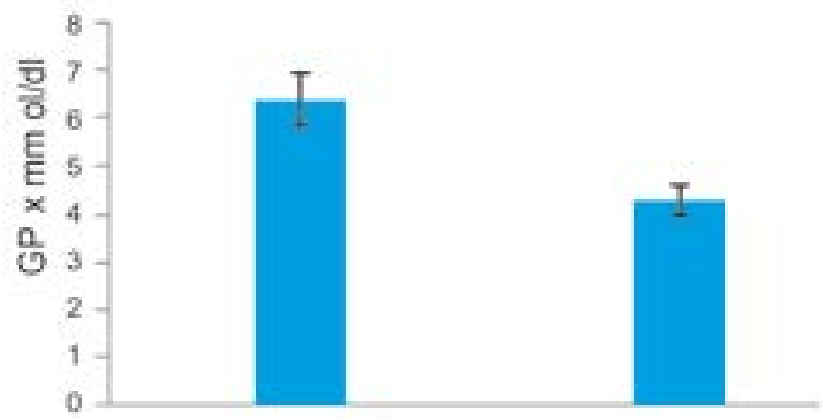

Figure (D)

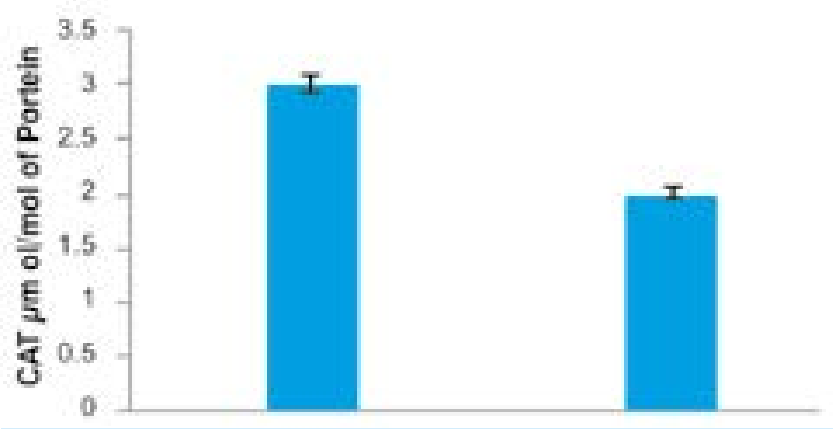

Figure (F)

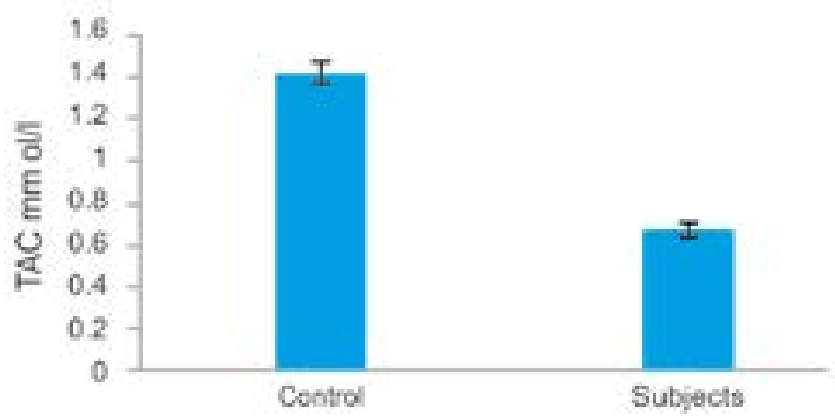

Figure (H)

Figure-2. Antioxidative profile of patients with cardiovascular diseases 
INFLAMMATORY BIOMARKERS PROFILE OF ATHEROSCLEROTIC PATIENTS Vs CONTROL Data regarding pro-inflammatory biomarkers profile showed (in figure-3) that the mean serum level of IL-6 in atherosclerotic disease patients and normal individuals was recorded as $6.35 \pm 0.64 \mathrm{pg} /$ $\mathrm{ml}$ and $4.13 \pm 0.46 \mathrm{pg} / \mathrm{ml}$ respectively with $\mathrm{p}$ value of 0.016 . The data interpretation of TNF-
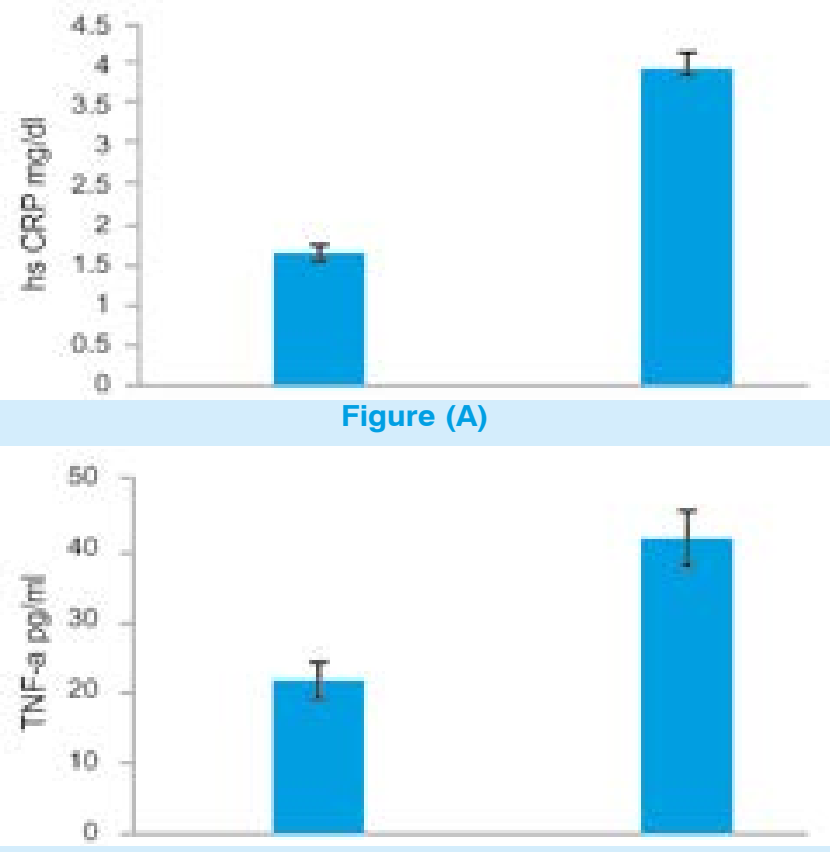

Figure (C)

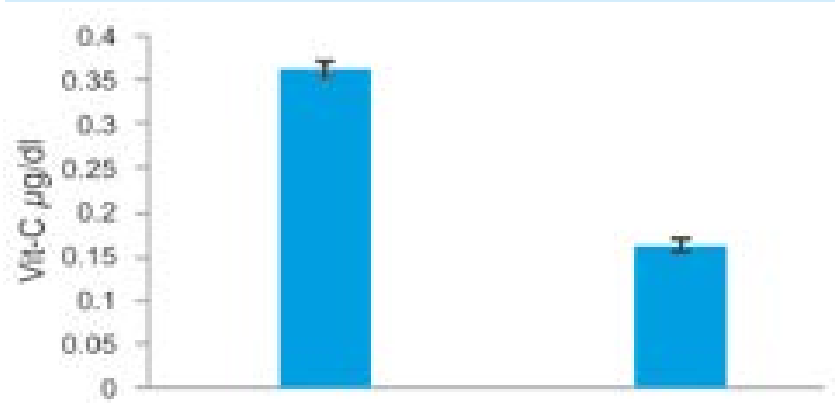

Figure (E)

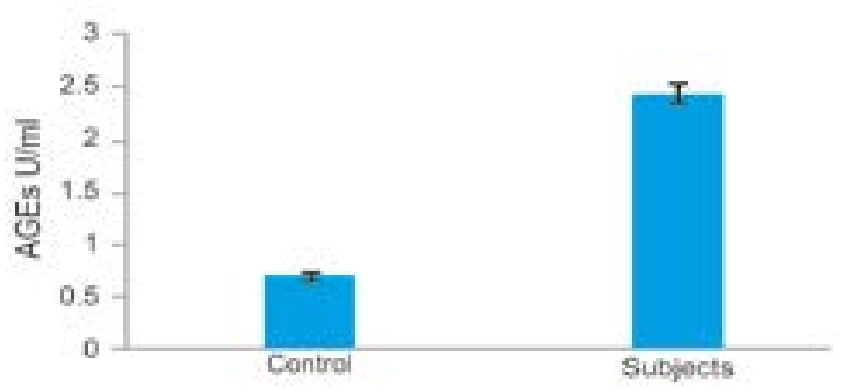

Figure (G) a showed statistically significantly $(p=0.037)$ increased levels in diseased group (41.25 \pm 3.65 $\mathrm{pg} / \mathrm{ml}$ ) in comparison with normal subjects $(21.29 \pm 2.35 \mathrm{pg} / \mathrm{ml})$. The mean hs-CRP serum levels in atherosclerotic diseased group were $(3.93 \pm 0.14 \mathrm{ng} / \mathrm{ml})$ whereas in control group $(1.68 \pm 0.06 \mathrm{ng} / \mathrm{ml})$, having significance $p=0.009$.
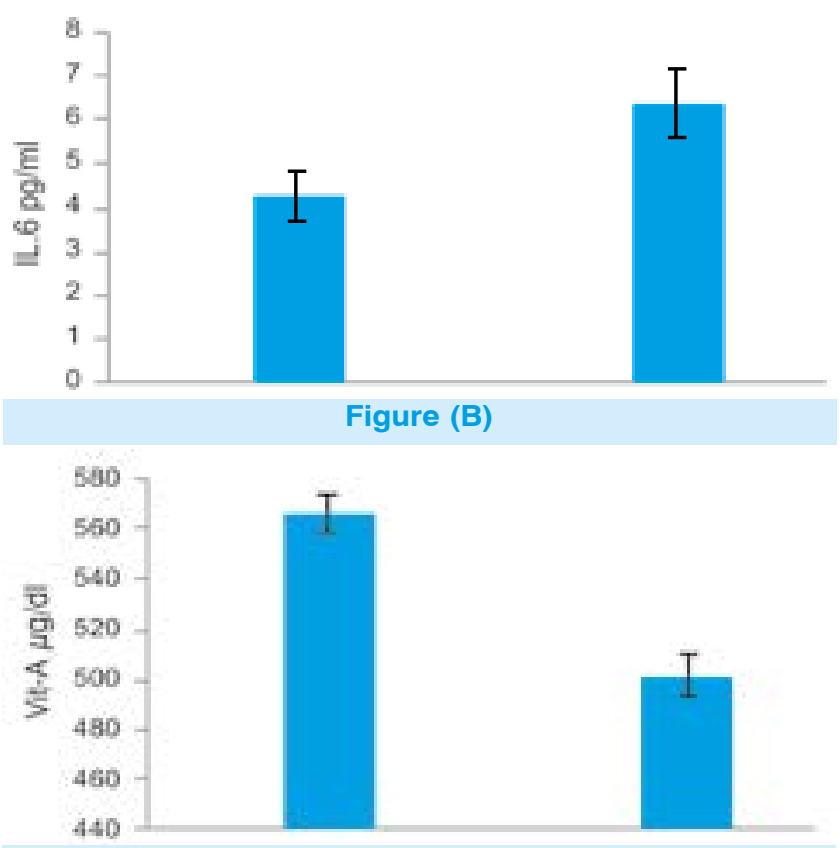

Figure (D)

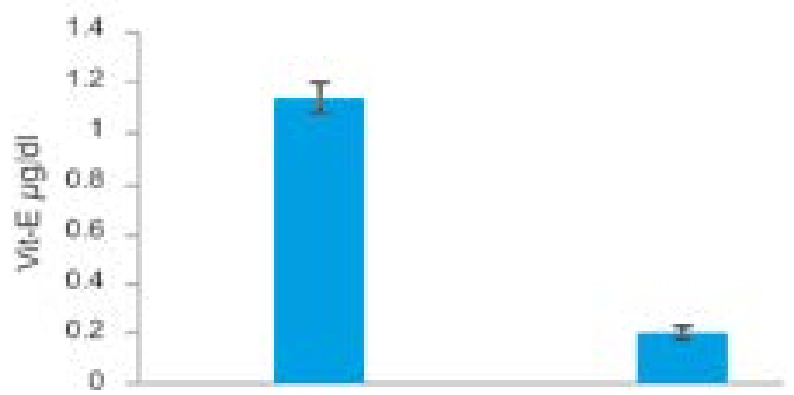

Figure (F)

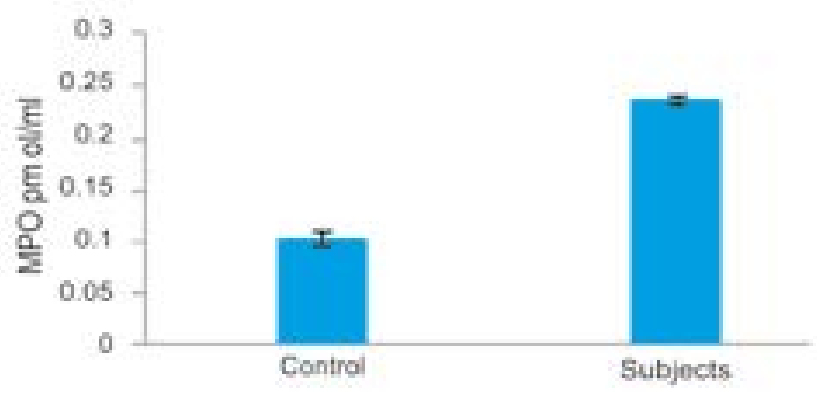

Figure (H)

Figure-3. Vitamins and Inflammatory of Patients with Cardiovascular Diseases 


\section{LIPID PROFILE OF CONTROL Vs}

\section{ATHEROSCLEROTIC PATIENTS}

The results depicted in figure-4 reflect an increased level of TCh in atherosclerotic patients $(217.56 \pm 10.99 \mathrm{mg} / \mathrm{dl})$ was recorded as compared to normal individuals $(188.56 \pm 7.75 \mathrm{mg} / \mathrm{dl})$. The mean levels of TG in both normal and diseased patients were $151.65 \pm 7.14 \mathrm{mg} / \mathrm{dl}$

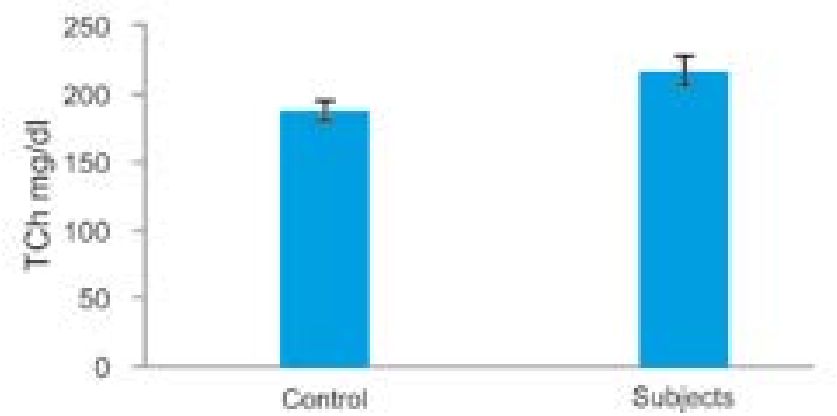

Figure (A)

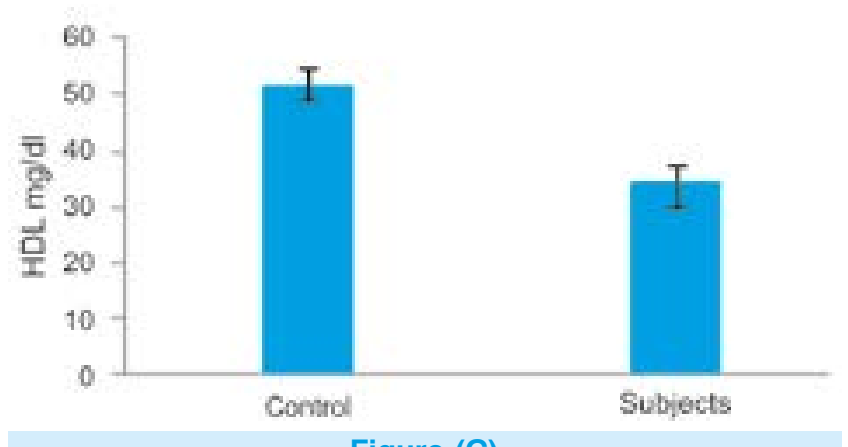

Figure (C) and $199.67 \pm 11.02 \mathrm{mg} / \mathrm{dl}$ respectively. Similarly the serum LDL levels in patients $(131.87 \pm 9.56 \mathrm{mg} / \mathrm{dl})$ were significantly increased in contrast to healthy individuals $(113.76 \pm 5.76 \mathrm{mg} / \mathrm{dl})$. In the case of $\mathrm{HDL}$, significantly high value was recorded in control group $(51.78 \pm 2.87 \mathrm{mg} / \mathrm{dl})$ as compared to diseased group $(33.76 \pm 3.85 \mathrm{mg} / \mathrm{dl})$. All of these markers were statistically significant.

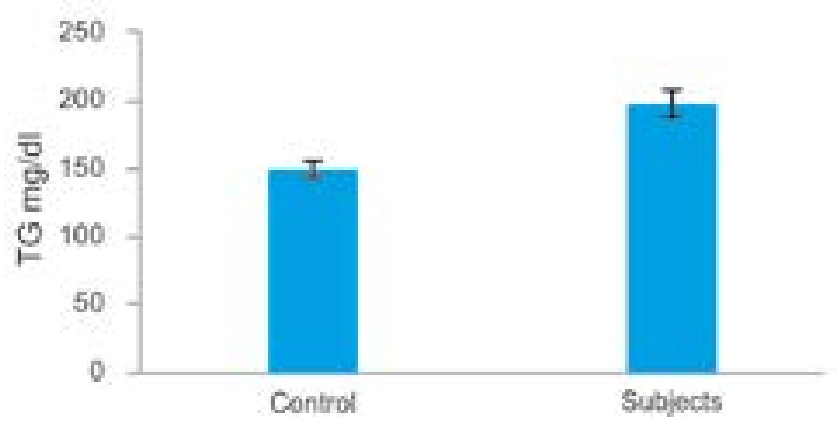

Figure (B)

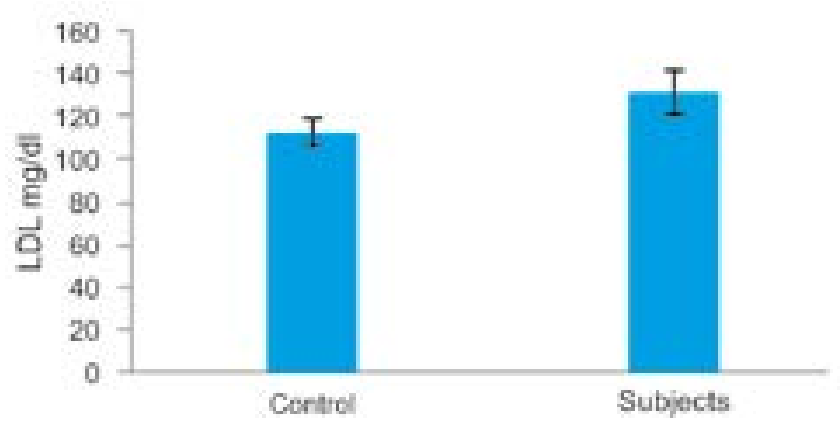

Figure (D)

Figure-4. Lipid Profile of Patients with Cardiovascular Diseases

\section{DISCUSSION}

Endothelial dysfunction induced by oxidative stress is considered as foremost and major contributor in the pathophysiology of atherosclerosis. Superoxide free radicals (O2-) produced by endothelial cells and macrophages rapidly react with nitric oxide (NO) to form peroxynitrite (ONOO-). Decrease bioavailability of $\mathrm{NO}$ and e-NOS (endothelial nitric oxide synthase) reduced activity are included in the initial signs of atherosclerosis. 25 Increased risks of CVDs are confined with reduced synthesis of NO but contrary to it, various studies revealed elevated NO levels in cardiovascular diseases. This increasing trend may be the result of compensatory mechanism which leads to the production of NO from the iso-forms of NOS (nitric oxide synthase).26 The present study reported elevated levels of nitric oxide in comparison with the normal individuals because of uncoupling of e-NOS, induction of i-NOS up-regulation and production of reactive $\mathrm{NO}$ intermediates that may promote atherosclerotic vascular disease. Peroxynitrite (ONOO-), the intermediate produced by $N O$ are involved in the oxidation of LDL into Ox-LDL, recognized by macrophage scavenger receptor pathway. Oxidation of LDL (low density lipoprotein), carrier of bad cholesterol, oxidized by ROS and interaction with macrophages convert them into foam cells, known as first lesion of atherosclerosis, as shown in figure-5. Uptake of daily dietary cholesterol increase $(0.024 \mathrm{mg} /$ dl) plasma cholesterol and increased in LDL and HDL cholesterol transporter protein that oxidized 
to cause CVD and atherosclerosis. ${ }^{27}$ It has been suggested the relevance of high TG levels in progression of atherosclerosis. ${ }^{28}$ it has been also revealed that the patient with atherosclerotic plaque, serum analysis showed the elevated levels of $\mathrm{LDL}^{29}$, increase in its levels make plaque rupture and made thrombus more pathogenic. Interpretation of above studies support our study results showing the elevated values of cholesterol, LDL, Triglycerides with the decrease levels of HDL.

Advanced glycated end-products (AGEs) formation is also induced by metallic catalyzed auto-oxidation of glucose and peroxynitrite, and also by reactive products like glycolytic intermediates. ${ }^{30}$ AGEs accumulation with age contribute to alter the structure and function of the cardiovascular system like vascular hardening, reduced central compliance of arteries, myocardial abnormalities, atherosclerosis and endothelial dysfunction which are further enhanced by the presence of diabetes, high blood pressure and renal diseases. AGEs is cross linked with LDL and reduce its ability to bind to its receptors thus increasing the LDL in circulation leading to its uptake with macrophage and thus forming foam cells. Increased inflammatory response induces ROS, promoting AGEs formation leading to increase in oxidative stress ${ }^{31,32}$ support our findings, high levels of AGEs increased the risk of atherosclerosis as illustrated in figure- 5 and AGEs are positively correlated with others factors of atherosclerosis like LDL and TG.

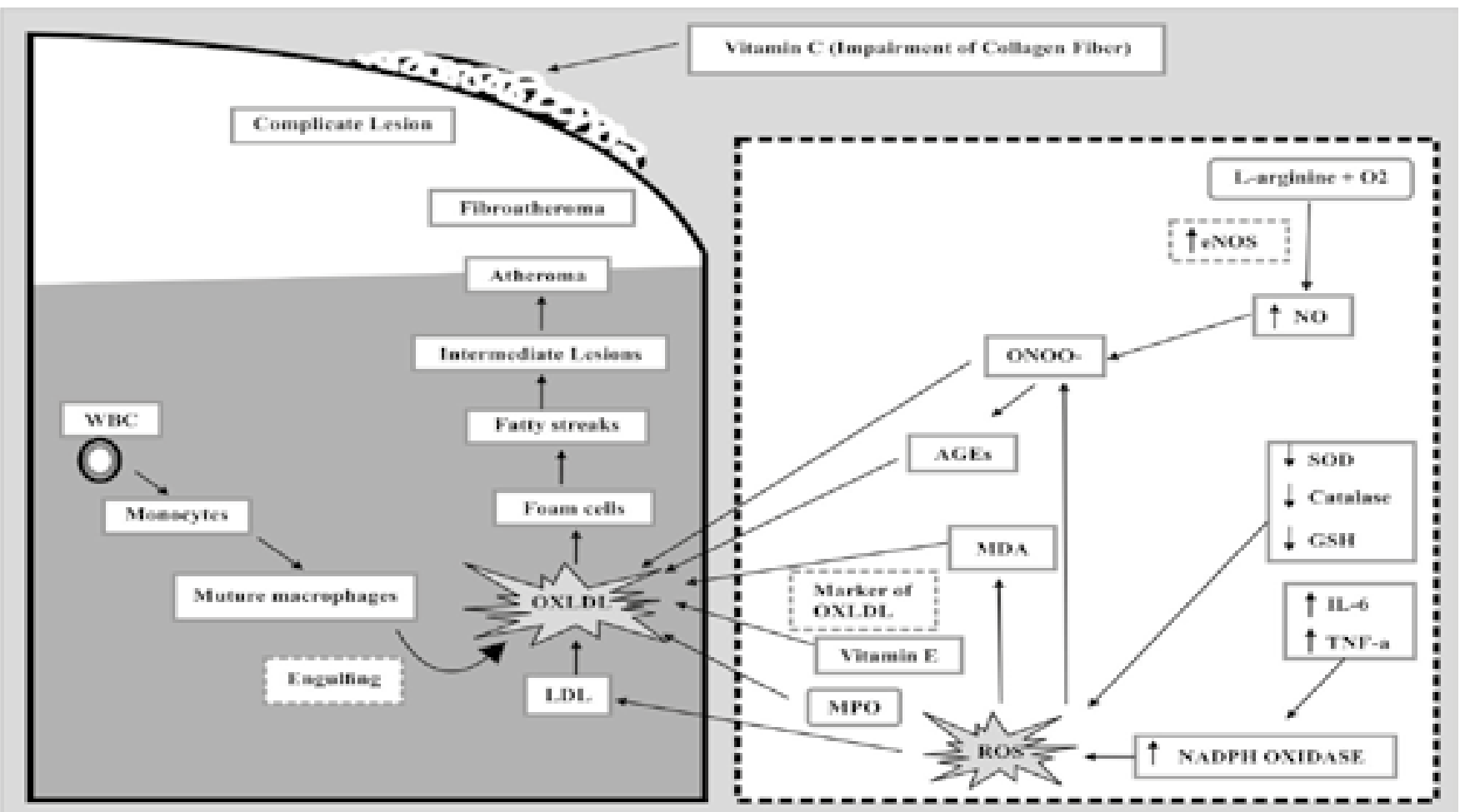

Figure-5. Reactive oxygen species (ROS) are generated due to decrease in antioxidants i.e. superoxide dismutase (SOD), catalase (CAT) and glutathione (GSH), and increase in inflammatory markers like interleukin-6 (IL-6) and tumor necrosis factor-alpha (TNF-a) which stimulate nicotinamide adenine dinucleotide phosphate-oxidase (NADPH -oxidase). ROS then oxidize low density lipoprotein (LDL) into oxidized-low density lipoprotein (Ox-LDL). ROS attack cell membrane to generate malondialdehyde (MDA) increases ox-LDL formation and also combine with nitric oxide (NO), as its formation is enhanced due to up-regulation of endothelial nitric oxide synthase (e-NOS) to form peroxynitrite (ONOO-). ONOO- is not only directly involved in ox-LDL production but also synthesizes advanced glycated end-products (AGEs), also important in ox-LDL. Increase in myeloperoxidase (MPO) levels also induces ox-LDL production. Monocytes become mature to form macrophages which engulf ox-LDL to form foam cells, initial lesion of atherosclerosis lead to fatty streaks and ultimately into complicated lesion that will block the artery completely. Deficient vitamin $\mathrm{C}$ results in damaging blood vessel wall, as important in collagen synthesis. Both vitamin $\mathrm{B}$ and $\mathrm{C}$ also act as antioxidants thus their deficiency lead to increase in ROS resulting in atherosclerosis. 
The antioxidant system consist of enzymatic antioxidants including SOD, CAT, GPx, GRx and non-enzymatic antioxidants such as Vit-A, Vit-E, Vit-C and glutathione which combat with oxidative stress produced in the body. In diseased condition, exacerbated ROS and RNS production overwhelmed and cause oxidative damage to lipids, DNA and proteins. Kayyum et al., (2002) also reported that patient of CVDs have decrease activity of SOD with enhancement in disease condition. ${ }^{33}$ CHD patients show low levels of antioxidant enzymes due to acute coronary infection, over production of ROS low down the anti-oxidant levels and down regulation of these antioxidant enzymes with the passage of time. ${ }^{34}$ Deficiency of vitamin $\mathrm{C}$ contributed in many diseases like CVDs and atherosclerosis progression. ${ }^{35}$ It has been proposed that mice fed with deficient vitamin A diet induce further complications related to atherosclerosis. ${ }^{36}$ The present study also revealed that the enzymatic (SOD, CAT, GPx and GRx) and non-enzymatic (Vit-A, Vit-C and glutathione) antioxidants level diminish with increase in oxidative stress and advancement in atherosclerosis.

Pro-inflammatory cytokines such as TNF-a and interleukins induced oxidative stress result in endothelial dysfunction and insulin resistance, contributing to atherosclerosis. ${ }^{37}$ ROS mediated NF-kB is the most vulnerable transcription factor to oxidative stress and associated with atherosclerosis by regulation of transcription genes involved in inflammation. ${ }^{38}$ Our study presented elevated levels of inflammatory markers (IL-6, TNF-a and hs-CRP) in atherosclerotic patients as compared to healthy individuals, similarly Thakur et al. (2011) also confirmed high levels of hs-CRP in coronary artery disease. ${ }^{39}$ Elevated IL-6 levels increase the instability mechanism of unstable plaque formation while TNF-a stimulates atherosclerosis by affecting the cholesterol homeostasis in macrophages and inflammation reactions that induces the vascular lesion formation. ${ }^{40,41}$ High levels of MPO involved in chronic inflammatory disease, lipid peroxidation and tissue injuries linked to the generation of atherosclerosis. 3-chloro-tyrosine used as marker of MPO involved in oxidation of LDL that was the initial reaction of atherosclerotic disease. It has been concluded that MPO and its oxidation products increase atherosclerotic plaque development. ${ }^{42}$ MDA formed as a byproduct of lipid peroxidation regulates the interaction between macrophages and Ox-LDL that result in atherosclerosis progression ${ }^{43}$, as displayed in figure-5. In the current study, MDA levels are elevated than normal patients due to high ROS generation mediating Ox-LDL production, similar findings were proposed by Arab et al. (2011). ${ }^{44}$

Obesity was the term used as increased in body fat that will affect weight and BMI of the body. South Asian peoples show the relation of increase in weight expressed to heart diseases. ${ }^{45,46}$

Our study showed increased BMI in atherosclerotic patients as compared to normal individuals which is concurrent with Kivimaki et al. (2008), reported that atherosclerosis risk factors are directly and indirectly raised by the elevated levels of BMI. ${ }^{47}$ Leukocytosis effect the endothelial layer through inflammation and oxidative damage. In the present study, WBCs increased in diseased patients as compared to controls due to infection and activated immune response which is in accordance with Ahmet et al. (2011), pointed leukocytosis involved in causing atherosclerosis and interaction of leukocytosis with other risk factors of atherosclerotic disease. ${ }^{48}$ Increase ROS production generates oxidized RBCs, after the oxidation RBCs release heme portion $(\mathrm{Hb})$ and deposition of red blood cells in plaque make plaque instable..$^{49,50}$ Red blood cells (RBCs) act as grip piper of oxygen and nitrogen reactive species due to its antioxidant activities. Increase in blood pressure (BP) will damage the arterial walls that further causes ROS generation initiating LDL oxidation further advances to fatty streaks ${ }^{51}$ which is in favour of our study.

\section{CONCLUSION}

Oxidative stress and inflammation play a pivotal role in the pathophysiology of atherosclerosis. Elevated levels of IL-6 increase the instability mechanism of unstable plaque formation while 
TNF-a stimulates atherosclerosis by affecting the cholesterol homeostasis in macrophages and inflammation reactions that induces the vascular lesion formation. Malondialdehyde (MDA) as a byproduct of lipid peroxidation also regulates the interaction between macrophages and OxLDL that result in atherosclerosis progression. So, better understanding of these extrapolative factors and their role in causing atherosclerotic disease is pre-requisite for effective health care and pharmacological intervention.

\section{Copyright@ 15 Sep, 2016.}

\section{REFERENCES}

1. Weisfeldt ML, Sugarman J, Bandeen-Roche K. Toward definitive trials and improved outcomes of cardiac arrest. Circulation. 2010; 121: 1586-1588.

2. Vincet HK, Taylor AG. Biomarkers and its potential mechanism of obesity induced oxidative stress in human. Int. J. Obes 2006; 30: 400-418.

3. Judkins $C P$, Diep $H$, Broughton BR, Mast AE, Hooker EU, Miller AA, Selemidis S, Dusting GJ, Sobey CG, Drummond GR. Direct evidence of a role for Nox2 in superoxide production, reduced nitric oxide bioavailability, and early atherosclerotic plaque formation in ApoE-/- mice. Am J Physiol Heart Circ Physiol.2009; 298: 24-32.

4. Thorne RF, Mhaidat NM, Ralston RJ, Burns GF. CD36 is a receptor for oxidized high density lipoprotein: implications for the development of atherosclerosis. FEBS letters.2007; 581(6): 1227-1232.

5. MadamanchiNR, RungeMS. Mitochondrial dysfunction in atherosclerosis. Circulation research.2007; 100(4): 460-473.

6. Inoue T, Node K. Vascular failure: a new clinical entity for vascular disease. Journal of hypertension.2006; 24(11): 2121-2130.

7. Vendrov AE, Hakim ZS, Madamanchi NR, Rojas M, Madamanchi C, Runge MS. Atherosclerosis is attenuated by limiting superoxide generation in both macrophages and vessel wall cells. Arterioscler Thromb Vasc Biol.2007; 27: 2714-2721.

8. Osganian SK, Stampfer MJ, Rimm E, Spiegelman D, $\mathrm{Hu} \mathrm{FB}$, Manson JE, Willett WC. Vitamin C and risk of coronary heart disease in women. J Am Coll Cardiol. 2003; 42: 246-252.

9. Monroe VS, Kerensky RA, Rivera E, Smith KM, Pepine CJ. Pharmacologic plaque passivation for the reduction of recurrent cardiac events in acute coronary syndromes. Journal of the American College of Cardiology.2003; 41(4):23-30.

10. Moron MS, DepierreJ, Mannervik B. Levels of glutathione, glutathione reductase and glutathioneS-transferase activities in rat lung and liver. Biochem. Biophys. Acta. 1979; 58: 267-278.

11. Aebi $H$. Methods in enzymatic analysis. $3^{\text {rd }}$ Ed. New York Academic Press. 1974; 674-684.

12. Kakkar P, Das B, Viswanathan PN. A modified spectrophotometric assay of superoxide dismutase. Ind. J. Biochem. Biophys. 1984; 21: 131-132.

13. Wendel A. Glutathione Peroxidases. In, Enzymatic Basis of Detoxification. Academic Press, New York. 1980; 333-353.

14. David M, Richard JS. In: Methods of enzymatic analysis, Bergmeyer, $\mathbf{J}$ and Grab $M$. (Eds), VerlagChemieWenhein Deer Field. Beach Floride. 1983; 358.

15. Rosenberg HR. Chemistry and physiology of vitamins. Inter Science Publishers Inc., New York. 1992; 452453.

16. Bayfield RF, Cole ER. Colorimetric determination of vitamin A with trichloroacetic acid. In: McCormick, D.B. and Wright, L.D., Eds. Methods in Enzymology, part F. Vitamins and Coenzymes. New York: Academic Press. 1980; 67: 189-195.

17. Chinoy JJ, Singh YD, Gurumurthi K. The role of ascorbic acid in growth, differentiation and metabolism of plants. J Plant Physiol. 1976; 22: 122.

18. Goldin A, Beckman JA, Schmidt AM, Creager MA. Advance glycation end products: sparking the development of diabetic vascular injury. Circulation. 2006; 114(6): 597-605.

19. Ohkawa H, Ohishi N, Yagi K. Assay for lipid peroxides in animal tissues by thiobarbituric acid reaction. Anal Biochem. 1979; 95: 351-358.

20. Engall E. Methods in Enzymology, Volume 70, Van Vunakais, H. and Langone, J. J. (eds.). Academic Press, New York. 1980; 419-492.

21. Fontes JD, Yamamoto JF, Larson MG, Wang N, Dallmeier D, Rienstra M, Schnabel RB, Vasan RS, Keaney JF $\mathrm{Jr}$, Benjamin EJ. Clinical correlates of change in inflammatory biomarkers: The Framingham Heart Study. Atherosclerosis. 2013; 228: 217-223.

22. Friedewald WT, Levy RI, Fredrickson DS. Estimation of the concentration of low-density lipoprotein cholesterol in plasma, without use of the preparative 
ultracentrifuge. Clin Chem. 1972; 18: 499-502.

23. Bijan S, Fardin M, Jalal K \& Ali K. Quantifying Serum TNF-Alpha Cut-Off Point for Predicting Coronary Stenosis Severity in a Population from Northern Iran. Middle-East Journal of Scientific Research. 2014; 21 (2): 307-313.

24. Bories $\mathrm{PN}$, Bories $\mathrm{C}$. Nitrate determination in biological fluids by an enzymatic one-step assay with nitrate reductase. Clin Chem. 1995; 4: 904-907.

25. Davignon J, Ganz P. Role of endothelial dysfunction in atherosclerosis. Circulation.2004; 109(23): 27-32.

26. Yoon Y, Song J, Hong SH, Kim JQ. Plasma nitric oxide concentrations and nitric oxide synthase gene polymorphisms in coronary artery disease. Clinical chemistry.2000; 46(10): 1626.

27. McNamara, Donald J. Dietary cholesterol and atherosclerosis. Biochimical Et Biophysica Acta (Bba)Molecular And Cell Biology Of Lipids.2000; 1529(1): 310-320.

28. Talayero BG, Sacks FM. The Role of Triglycerides in Atherosclerosis. Curr Cardiol Rep.2011; 13(6): 544552.

29. Anthony C. LDL Cholesterol: Bad Cholesterol, or Bad Science? Journal of American Physicians and Surgeons.2005; 10: 83-89.

30. Thornalley PJ. Use of aminoguanidine (Pimagedine) to prevent the formation of advanced glycation end products. Archives of Biochemistry and Biophysics. 2005; 419: 31-40.

31. Peppa M, Uribarri J, Vlassara $H$. The role of advanced glycation end products in the development of atherosclerosis. CurrDiab Rep.2004; 4(1): 31-36.

32. Chang JB, Chu NF, Syu JT, Hsieh AT, Hung YR. Advanced glycation end products (AGEs) in relation to atherosclerotic lipid profiles in middle aged and elderly diabetic patients. Lipids in Health and Disease.2011; 10: 228.

33. Kayyum-Shaikh A, Suryakar AN. Oxidative stress and antioxidant status before and after supplementation of $A-Z$ anti-oxidant tablets in coronary artery disease. Biom Res.2009; 20: 136-140.

34. Giordano FJ. Oxygen, oxidative stress, hypoxia, and heart failure. J Clin Invest. 2005; 115(3): 500-508.

35. Ginter E. Chronic Vitmain C deficiency increase the risk of cardiovascular disease. Bratislleklisty. 2007; 108(9): 417-421.
36. Gatica LV, Vega VA, Zirulnik F, Oliveros LB, Gimenez MS. "Alterations in the lipid metabolism of rat aorta: effects of vitamin A deficiency." Journal of Vascular Research. 2006; 43(6): 602-610.

37. Chen X, Xun K, Chen L, Wang Y. TNF-a, a potent lipid metabolism regulator. Cell biochemistry and function.2009; 27(7): 407-416.

38. Morgan MJ, Liu ZG. Crosstalk of reactive oxygen species and NF-kBsignaling. Cell research. 2011; 21(1): 103-115.

39. Thakur S, Gupta S, Parchwani H, Shah V, Yadav V. HsCRP-A potential marker for coronary heart disease. Indian Journal of Fundamental and Applied Life Sciences.2011; 1: 1-4.

40. Liuzzo G, Buffon A, Biasucci LM, Gallimore JR, Caligiuri G, Vitelli A, Altamura S, Ciliberto G, Rebuzzi AG, Crea $F$, Pepys $M$. Enhanced inflammatory response to coronary angioplasty in patients with severe unstable angina. Circulation.1998; 98(22): 2370-2376.

41. Elkind MS,Cheng J,Boden-Albala B, Rundek T, Thomas J, Chen H,Rabbani LE, Sacco RL. Tumor Necrosis Factor Receptor Levels Are Associated With Carotid Atherosclerosis. Stroke. 2002; 33: 31-38.

42. Nicholls SJ, Hazen SL. Myeloperoxidase, modified lipoproteins, and atherogenesis. Journal of lipid research.2009; 50: 346-351.

43. Slatter DA, Bolton $\mathrm{CH}$, Bailey AJ. The importance of lipid-derived malondialdehyde in diabetes mellitus. Diabetologia.2000; 43: 550-557.

44. Arab S, Khazaai H, Hambali Z, Ahmad Z. Homocysteine and Malondialdeyde (MDA) Levels Associated with the Occurrence of Cardiovascular Disease (CVD) in Chronic Renal Failure (CRF) in Malaysia. Global Journal of Health Science.2011; 3(1): 119-127.

45. McKeigue PM, Ferrie JE, Pierpoint T, Marmot MG. Association of early-onset coronary heart disease in South Asian men with glucose intolerance and by hyperinsulinemia. Circulation. 1993; 87: 152-161.

46. Venkatramana P, Reddy PC. Association of overall and abdominal obesity with coronary heart disease risk factors: comparison between urban and rural Indian men. Asia Pac J Clin Nutr. 2002; 11: 66-71.

47. Kivimaki M, Smith GD, Timpson NJ, Lawlor DA, Batty GD, Kähönen M, Juonala M, Rönnemaa T, Viikari JS, Lehtimäki T, Raitakari OT. Lifetime body mass index and later atherosclerosis risk in young adults: examining causal links using Mendelian randomization in the 
Cardiovascular Risk in Young Finns study. European Heart Journal.2008; 29: 2552-2560.

48. Ahmet $A$, Canpolat $U$, Yorgun $H$, Kaya EB, Sunman $\mathrm{H}$, Demiri $\mathrm{E}$, Taher A. Total white blood cell count is associated with the presence, severity and extent of coronary atherosclerosis detected by dualsource multislice computed tomographic coronary angiography. Cardiol J. 2011; 18(4): 371-377.

49. Kolodgie FD, Gold HK, Burke AP, Fowler DR, Kruth HS, Weber DK, Farb A, Guerrero LJ, Hayase M, Kutys R, Narula J, Finn AV, Virmani R. Intraplaquehemorrhage and progression of coronary atheroma." The New England Journal of Medicine. 2003; 349(24): 23162325.

50. Muda P, Kampus P, Zilmer M, Zilmer K, Kairane C, Ristimäe T, Fischer K, Teesalu R. Homocysteine and red blood cell glutathione as indices for middle-aged untreated essential hypertension patients". Journal of Hypertension. 2003; 21 (12): 2329-2333.

51. Edward FD. Hypertension and atherosclerosis. The American journal of medicine 1969; 46(5): 735-740.

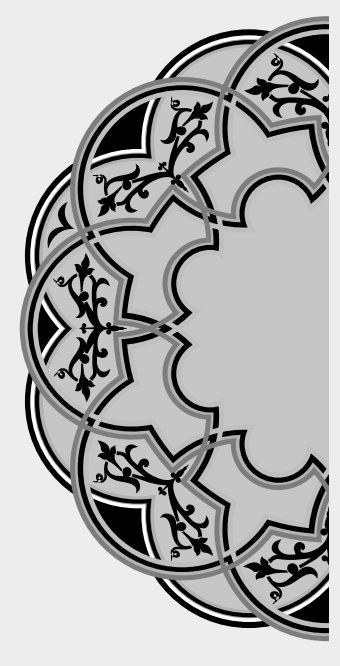

\title{
"You have two ears and one mouth. Follow that ratio. Listen more, talk less."
}

\author{
Unknown
}

\section{AUTHORSHIP AND CONTRIBUTION DECLARATION}

\begin{tabular}{|c|c|c|c|}
\hline Sr. \# & Author-s Full Name & Contribution to the paper & Author $=$ s Signature \\
\hline 1 & M. Abdul Basit Ashraf & 1st Author & \\
\hline 2 & Razia Rizwan & Co-Author & \\
\hline 3 & Mehwish Arooj & Co-Author & plosere \\
\hline 4 & Arif Malik & Co-Author & \\
\hline 5 & Sarmad Bashir & Co-Author & 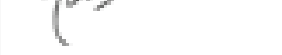 \\
\hline
\end{tabular}

